\title{
The psychological effects of unemployment: a review of the literature
}

\author{
Keith Macky* and Hilary Haines**
}

The literature on the psychological effects of unemployment is reviewed, with particular attention being paid to the somewhat scarce New Zealand literature on the subject. Studies conducted at the macrosocial level are discussed, followed by studies that focus on the individual, with respect to physical health, mental health and psychological well-being, and social attitudes. The differential effect of unemployment on various social groups is examined, and the methodological deficiencies in some of the studies reviewed, are summarized. In conclusion, it is suggested that the documented psychological ill-effects of unemployment should make us view rising levels of unemployment with concern.

Research into the psychological effects of unemployment has been conducted in two waves. The first was a response to the depression of the 1930s, when psychologists from the United States, Britain and Europe put their newly developed methods of research and testing to a practical use (see the comprehensive review by Eisenberg and Lazarsfeld, 1938). After the depression, research on unemployment dwindled, focusing on the so-called "hard-core" unemployed who were presumed unable to obtain or hold down jobs because of personal characteristics, rather than because of economic conditions. With rising unemployment in the Western world during the 1970s, the questions of the 1930s were reinvestigated, with the benefit of forty years of advances in experimental design and psychological testing; although it must be said that modern researchers have not always availed themselves of good techniques.

This renewed interest in the psychological effects of unemployment was crystallized by Marie Jahoda (1979), an eminent social psychologist who had been the principal author of a notable early work on unemployment (Marienthal: the Sociography of an Unemployed Community). She raised some crucial questions about the relationship between the 1930 s findings and the unemployed today. Three major changes in social conditions between then and now could affect the validity of any generalizations from early studies to the current situation: (1) With the advent of the Welfare State, the unemployed in Western countries, while still disadvantaged financially compared to those in work, do not as a rule suffer the severe economic hardship that the unemployed of the 1930s had to face. How much did factors such as poor nutrition, for example, contribute to the well-documented psychological ill-effects? (2) The unemployed now are considerably better educated than they were during the 1930s. This could result in greater disappointment because of increased expectations, or it might enable the unemployed to make more constructive use of their leisure time; (3) Changes in the social value attached to work may have ameliorated the deleterious effects of unemployment. Jahoda also reminded her readers that we now have an extensive literature on the psychology of work which should enable us to better comprehend the meaning of lack of work. As Swinburne (1981) points out, " . . the meaning of the loss of work depends on the meaning which work had originally ..."(p.53).

The literature on the psychological effects of unemployment is now growing extremely

* Psychology Department, University of Auckland.

** Psychology Department, University of Auckland and Mental Health Foundation of New Zealand. 
rapidly and, as this review will show, is demonstrating that despite the changes mentioned by Jahoda, today's psychology of the unemployed is remarkably similar to earlier portraits. This review will discuss the relationship between unemployment and physical health, mental health and psychological well-being, and social attitudes. Reference will be made, where possible, to New Zealand research. Although there is little to speak of, the 1981 Mental Health Foundation and New Zealand Psychological Society joint symposium on unemployment indicates an increasing local interest in the area. It is important that New Zealand studies be carried out rather than overseas findings be imported wholesale, since psychological studies of this nature may be culture bound. (As a matter of interest, we have found no reference to any psychological studies of unemployment in New Zealand during the 1930s.)

\section{The Effects of Unemployment: Studies of Social Indicators}

Before discussing studies of individuals, the innovative studies at the macrosocial level of analysis initiated by Harvey Brenner $(1973,1977)$ will be examined. Taking three economic variables, the inflation rate, the unemployment rate and per capita income, Brenner related cyclical fluctuations in these variables to seven indices of social stress in the United States. Analysing the period from the Great Depression to the 1970s he demonstrated that a sustained 1 percent rise in unemployment led to a 4.1 percent increase in suicides, a 3.4 percent increase in first admissions to state mental hospitals, a 4 percent rise in admissions to state prisons, and a 6 percent rise in homicide rates. Mortality from cirrhosis of the liver, together with cardiovascular and renal diseases also increased, as did rates of mortality overall (Brenner, 1973; 1977). Increases in psychopathological disturbances, such as homicides and suicides, were evident within one year of the rise in the unemployment rate, whereas the increases in the mortality rates showed a time lag of two to three years for most age groups and for both sexes. The other two social indicators used by Brenner (income and inflation) also showed varying relationships to the indicators of social stress, but it was the unemployment rate that demonstrated a relationship most consistently. This relationship was found regardless of age, sex, socio-economic class and ethnic grouping. The relationship between economic downturn and increase in admissions to mental hospitals is particularly convincing when, as Brenner demonstrates, it cannot be attributed to any increased availability of facilities for psychiatric care. Ahr et al. (1981), who correlated admissions to eight Missouri psychiatric facilities with unemployment statistics, confirmed Brenner's findings.

Brenner (1979) extended his analysis to England and Wales over the years 1936 to 1976 and demonstrated a positive relationship between unemployment and mortality rates which held across all age groups.

Suicide rates were also studied in relationship to unemployment by Olsen and Lajer (1979) in a comprehensive study of bricklayers, carpenters and cabinetmakers in Denmark. Over a period of five years, they found that periods of unemployment had occurred more frequently among those who died by "violent death" compared to those who died of natural causes. The "violent death" group comprised those who died either by suicide or accidents, with no difference being found in the frequency of periods of unemployment in either group. A New Zealand study of suicides in the Wellington Hospital Board region for 1978 (Howell et al., 1980) found that, among occupational groupings, the unemployed had the highest rates of "fatal self-harm", with a rate of 26 per 10,000 population; the next highest rating was obtained by retired people and service occupations, with 2 per 10,000. The unemployed were also the highest group in the "non-fatal self-harm" category, with a rate of 180 per 10,000 as compared to 38 per 10,000 for service occupations, the group with the next highest rating. Howell et al. also found that females and young people were more likely to attempt suicide; these two groups are also more at risk of being unemployed. Of course data on occupational status prior to suicide or suicide attempts does not establish a causal linkage between unemployment and suicide: suicidal people 
may stop working. Nevertheless, the proneness of the unemployed to suicide is so striking (and it is clear that in certain particular instances unemployment was in fact the precipitating cause) that the figures do compel reflection. ${ }^{1}$

A recent New Zealand study by MacDonald et al. (1982), based on Brenner's methodology, compared changes in the percentage of the labour force unemployed to rates of suicide, first admissions to mental hospitals, homicides and post-neonatal infant mortality. Their findings are consistent with those of Brenner's, although they were constrained by the limited availability of health data from 1979 onwards, data which might reflect the effects of the sharp upturn in unemployment from 1975 onwards. The suicide rate showed a significant rise in the 1930s corresponding to the Depression years, and rose again in 1977. Homicide rates also increased in the 1930s and again in the last five years. First admissions to mental hospitals, while showing an overall decline over the past two decades (reflecting the move towards more out patient treatment), appeared to have steadied in the last two years for which data was available, 1977 and 1978. Post-neonatal infant mortality rates showed a steady decline from high levels in the 1930s and now appear to have steadied, if not increased. MacDonald et al.'s prediction that the health consequences of New Zealand's increasing unemployment levels will be demonstrated in national health statistics is a cause for concern.

From the above studies it would appear that a clear relationship between periods of high unemployment and indicators of social stress, such as suicide and rates of psychiatric hospitalization, has been established. However, Brenner has not been without critics. Eyer (1976a), in his review of Brenner's Mental Illness and the Economy (1973) criticized Brenner on several grounds: his failure to provide extensive tables of basic data; his use of Fourier analysis for time series data containing cyclical fluctuations; and his having introduced possible distortions through data transformations such as exercising choice over which time lags to employ and for breaking time series into short fragments. Brenner was also accused of interpreting the data so as to fit in with his own particular political attitudes. Eyer's criticism brought a defence from Brenner (1976) and a counter reply from Eyer (1976b). Apart from such theoretical criticisms, Brenners' empirical findings have not invariably been replicated. For example, Lester (1970) found a negative correlation between unemployment and suicide in a study of Pennsylvanian statistics from 1954 to 1961. An Australian study found that in the 1960s, which was a period of economic prosperity and full employment, male suicides rose to levels comparable with the 1930s and female suicides were the highest in the century (Goldney and Burvell, 1980).

But criticisms and contrary evidence notwithstanding, Brenner's work does seem to have established that in general rises in the unemployment rate are followed by changes in social indices suggestive of stress. However, social indicators are a crude measure of the mental and physical health of a society and do not contribute to any subtle understanding of the psychological effects of unemployment. The experience of unemployment may well lead to depression, anxiety or stress-related physical symptoms, but this does not necessarily lead to an individual utilizing national health-care services. The role of other variables, such as the length of unemployment, family responsibilities and so on is not clarified in the type of study discussed so far. Studies at an individual level of analysis are essential, and will be examined in the following sections.

\section{Unemployment and Physical Health}

It is assumed that the relationship between unemployment and poor health is largely mediated by psychological factors rather than environmental ones such as poor nutrition (although this type of variable may well play a role). Possibly the only longitudinal investi-

1. The interested reader is referred to an earlier New Zealand study (Porterfield and Gibbs, 1960) of suicide and its relationship to occupational prestige and changes in prestige. Unfortunately in this study the unemployed were not able to be separated out from other non-working groups. 
gation in this area is reported in publications by Cobb and Kasl (1972), Kasl, Gore and Cobb (1975) and Gore (1978), who studied physiological variables in married male bluecollar workers from two industrial plants that closed down: one in a large urban area and the second in a small rural town. The control group comprised blue-collar workers in stable employment. Over a period of two years, the men were interviewed by public health nurses at the time periods of: "anticipation" (of plant closure), "termination", unemployment, probationary re-employment and stable re-employment. They found increased levels of uric acid in the anticipation phase, which dropped to normal on re-employment; higher blood pressure in the anticipation, unemployment and probationary re-employment phases than when later stably re-employed; and increased chloresterol levels in the unemployment period, which later fell on obtaining a new job (Cobb and Kasl, 1972). Their sample had a suicide rate thirty times that expected for blue-collar men of the same age. There were increases in cases of hypertension and peptic ulcer symptoms (this also applied wives); colds and "intestinal flu" were also more frequent. it.

In an analysis of subjective data obtained from a daily health diary kept by their respondents, Kasl, Gore and Cobb (1975) found that the men reported more feelings of not being as well as usual in the anticipation phase than when stably re-employed; however there was no difference in this respect between the unemployment and employment phases. Men showing poorer general adjustment reported more feelings of "unwellness" in the phases following the anticipation of plant closure, indicating a slower recovery from the stressful impact of job loss. For the urban sample, those who subjectively rated the experience of job loss as being more severe, together with those who experienced a lot of job changes in the two-year period of the study, also reported more feelings of being unwell. This latter group, and those who were still unemployed in the later phases of the study (one to two years after plant closure), reported increasing restrictions on their usual activities due to illness or injury compared to those in stable employment or those who rated the experience as not so severe. The latter group reported decreasing restrictions on their activities.

Gore (1978) further investigated urban-rural differences between the two groups. The earlier study had shown that rural men experienced more weeks of unemployment, yet showed less impairment on some health indicators than the urban men did. She found that the urban unemployed had a significantly lower level of social support than the rural unemployed. Those with low levels of social support showed higher levels of (and more marked changes in) the measures of illness symptoms and cholesterol levels. Thus social support would seem to be a factor in moderating the negative health consequences of unemployment (cf. Dimsdale et al., 1979, for a full discussion of the role of social supports in medical care.)

Some further evidence for the physical health effects of job loss derives from a recent Australian study by O'Brien and Kabanoff (1979). They found that the unemployed, who had been identified through a multi-stage cluster sampling method from metropolitan Adelaide households, reported a significantly higher incidence of symptoms than did the employed. These symptoms were classified into physical (organic) and non-physical; the non-physical ones were used to form a scale which was held to measure stress. The unemployed reported higher levels of physical symptoms, such as heart trouble and shortness of breath, which, the authors hypothesized, may have contributed to unemployability (at least for manual work) rather than have resulted from unemployment. The unemployed had a greater incidence of minor physical complaints such as bronchitis, colds, allergies, etc, and a lower incidence of problems such as back trouble, knee injuries, varicose veins, shoulder injuries and hayfever, all of which could have resulted from work conditions. The unemployed showed a higher incidence of stress. The number of stress symptoms reported overall showed no significant difference between the two groups but, for 19 out of the 21 symptoms, the unemployed showed higher rates. There was a positive correlation $(0.36)$ between stress and the time spent looking for work. 


\section{Unemployment, Mental Health and Psychological Well-being}

The literature on the psychological effects of unemployment contains many studies which seek to examine the impact of unemployment on mental health or psychological well-being, using a multitude of different theoretical approaches and measures. Our review of this area will discuss the relevant studies in several clusters: viz impressionistic accounts and case histories; studies looking at the use of time; studies utilizing subjective measures of well-being; studies of self-esteem; developmental models; locus of control and attribution studies; and those that utilize the General Health Questionnaire. Finally, attention will be paid to factors which have a moderating influence on mental health and psychological well-being.

\section{Impressionistic Accounts and Case Histories}

Eisenberg and Lazarsfeld introduced their 1938 review by saying: "When we try to formulate more exactly the psychological effects of unemployment, we lose the full, poignant, emotional feeling that this world brings to people." (p.358). They then referred their readers to a number of contemporary novels, plays and case studies so that a more personal view could be obtained. This statement is just as true today, and the reader is referred to the following accounts which include descriptive accounts of the psychological effects of unemployment: Marsden \& Duff, 1975; Gould and Kenyon, 1972; Hill, 1978; Hayes and Nutman, 1981. It is clear from such accounts that unemployment is psychologically destructive. Over half of Daniel's (1974) British sample reported boredom, depression and feelings of failure. On the New Zealand scene, some studies report subjective data and there is, of course, a great deal of such information in magazine and newspaper articles. Hancock's (1981) study of women in Dunedin after the collapse of the Mosgiel textile industry indicated that loneliness, boredom, depression, and anxiety were common responses to job loss. The Christchurch Employment Advisory Committee's (1979) study of unemployed youths found that boredom and dissatisfaction with life were common; feelings of loneliness, depression and loss of confidence were also reported, although less commonly. Haines and Macky's (1982) study of school leavers produced such comments as "degraded", "useless", "hopeless", "left out", and "bored".

\section{Use of Time}

Since boredom is one of the most common psychological consequences of unemployment, a number of studies have investigated how the unemployed spend their time. Jahoda and Lazarfeld's (1933) study of the Austrian village of Marienthal, where virtually all the adult population were unemployed, showed that leisure activities did not expand to fill the gap left by lack of work. Membership of clubs and voluntary organizations actually decreased, as did borrowing from free public libraries. Obviously the decrease in these activities is not attributable to lack of money, but it is suggestive of apathy or depression. Modern case histories document widespread feelings of boredom - the unemployed often feel that it's not worth getting up in the morning. O'Brien and Kabanoff (1979) in a systematic study of the leisure pursuits of the unemployed, found that the unemployed engaged in more varied and skilful activities than did the employed, but their activities involved less interaction with others. Turtle et al.'s (1979) study of Sydney youth painted a similar picture of social withdrawal rather than decreased activity. Two New Zealand studies on youth (Christchurch Employment Advisory Committee, 1979; Haines and Macky, 1982) found no obvious decrease in activities. Haines and Macky's respondents slept more in the daytime, spent more time doing nothing, listening to the radio or watching television, than when they had been at school, but they also spent more time on 
hobbies, helping around the home and going out with friends. Two thirds of the unemployed school leavers thought that boredom was the worst thing about being unemployed. Jahoda (1979) points out that some important functions of work are that it helps to impose a time structure on the day, that it enforces activity and that it involves shared activity outside the nuclear family. All these are probably important to psychological well-being.

\section{Measures of Psychological Well-being}

Studies which have compared groups of unemployed and employed people using scales measuring psychological well-being have often, but not always, found significant differences between the two groups. Bradburn (1969), comparing male and female unemployed chief wage earners with employed chief wage earners, did find significant differences in well-being, with anxiety and worry particularly characteristic of the unemployed. Using Bradburn's measures, together with a "present life satisfaction scale", Warr (1978) found that a sample of redundant steel workers who had not yet obtained a job achieved significantly lower scores than did those who had located a job. The unemployed reported greater anxiety, both general and specifically about money, health, their job situation and the world situation. In a study of 78 unemployed men selected from those attending an Unemployment Benefit Office, Hepworth (1980) found that the unemployed had significantly poorer subjective well-being, as measured by Warr's Present Life Satisfaction Scale, then had the re-employed steel workers of Warr's study. O'Brien and Kabanoff's Australian study found slight but insignificant differences between employed and unemployed on a different scale of life satisfaction. Singh and Kumar (1976) found that the more qualified unemployed reported greater anxiety than those who were less qualified, and that their anxiety increased with the length of time spent unemployed.

\section{Self-esteem}

Tiffany et al. (1970) found that chronically unemployed manual workers held a poor opinion of themselves but failed to demonstrate any causal linkage between unemployment and low self-esteem. Hartley (1980), in a report on unemployed managers on a retraining course, did not find lowered self-esteem compared with employed managers, nor was selfesteem related in any way to length of unemployment; however, being on a re-training course could have regenerated lost self-esteem. Gurney (1980), who tested Australian school pupils before and after leaving school, showed that unemployment did not decrease self-esteem, but that employment (for girls but not for boys) increased self-esteem. But both Hartley and Gurney emphasized the great individual variability in the response to unemployment, with Gurney and Taylor (1981) pointing to some who apparently showed no ill effects of the experience.

\section{Developmental Models}

A number of writers have used a developmental model to discuss changes in psychological well-being attendant upon unemployment. Jahoda (1979), recalling the early studies, presented a model whereby the initial response to unemployment was one of shock, followed by a period of constructive adaptation when the unemployed person engaged in active job-seeking, often enjoyed their free time, and felt optimistic about their chances of obtaining work. With failure to obtain work, a period of pessimism ensued, with increasing boredom, and declining self-respect. The final stage was characterized by "despair or fatalistic apathy" (p.310). On the other hand, Hill (1978) presented a model based on case studies, which featured more adaptive responses. Initial feelings were of denial, or perhaps even optimism; then there was a phase where the euphoria wore off and 
depression and inertia developed; and finally a phase, after perhaps nine months of unemployment, where lifestyle was adapted to a lower standard of living, serious jobhunting declined and the depression associated with the second phase was even alleviated. Swinburne (1981), in her study of unemployed managers on a retraining scheme, also reported an initial phase of shock, but found that although some of the men in her sample had been unemployed for over six months or even for over a year, none had reached a stage of pessimism. They had not resigned themselves to unemployment, although she remarked that they appeared to be making conscious efforts to hold pessimism at bay. It must be remembered, though, that her sample was unrepresentative of the wider pool of the unemployed.

There does seem to be some evidence, then, for a cyclical account of the psychological effects of unemployment. It is agreed that the initial stages involve shock and perhaps even optimism, that the early period is characterized by constructive attempts to find a job; failure to find a job, for most groups, leads to depression and anxiety; and finally a more settled phase develops characterized by low job-seeking. The affective tone of this latter period may be despair or apathy, or may be less severe. The influence of moderating variables, such as age and occupational status needs further study.

\section{Locus of Control and Attribution}

It has been suggested that unemployment might produce a heightened external locus of control, because the attempts of the unemployed to manipulate their environment go unrewarded. Tiffany et al. (1970), in their study of chronically unemployed Americans found that they showed a higher external locus of control (i.e. a strong belief in the idea that outside forces control one's behaviour) than did men from a socieconomically comparable group. O'Brien and Kabanoff (1979) confirmed this difference between the employed and unemployed with a well-selected Australian sample. Haines and Macky (1982) showed slight but insignificant differences between employed and unemployed New Zealand school-leavers in terms of locus of control.

Hesketh (1982), in a report on a current study of some unemployed people in Palmerston North, describes an attempt to develop a more complex theoretical model of the self-attributions of the unemployed than that of the simple internal/external dimension of the locus of control scale. She predicts that the unemployed among a group of unemployed will attribute their status to external conditions such as the economy, but the solitary unemployed will attribute their status to internal conditions, i.e. they will blame themselves. Among the latter, the experience of unemployment might be another failure in a series of failures, and they might blame themselves more than the person who has previously experienced success in their endeavours. If failure to get a job is prolonged and consistent, then attributions to external conditions would be expected, whereas internal attributions would seem more likely early in the job search. In the literature on locus of control, it is commonly assumed that it is healthy to have an internal locus, since people then hold themselves responsible for what happens to them: they are "masters of their fate" rather than pawns in someone else's game. However, as Hesketh suggests, the effects of internal or external attributions could be paradoxical. Internal attributions could lead to self-blame and depression, or to heightened efforts to obtain a job. External attributions could lead to hopelessness and despair, or to a healthy adaptation to the situation of unemployment. The outcome of her present studies will be awaited with interest.

\section{General Health Questionnaire Studies}

The General Health Questionnaire (G.H.Q.), developed by Goldberg (1972) is a selfadministered screening test designed for detecting non-psychotic psychiatric illness. Hepworth (1980), in the previously mentioned study of unemployed men, found they had 
higher scores on the G.H.Q. than did workers in an engineering firm (a high score means a greater likelihood of being diagnosed as suffering from a non-psychotic psychiatric illness). Banks et al., (1980) and Stafford et al. (1980) obtained similar results in a study comparing a large number of employed and unemployed poorly qualified school-leavers. Warr (1980) reported results from the same sample eight months after the original interviews and investigated the influence of changes in employment status. The results showed that while the G.H.Q. scores of the unemployed were higher than those of the employed, there was also a corresponding rise in the G.H.Q. scores of those who had become unemployed since the first interview. Conversely, those who were originally unemployed but who had subsequently obtained a job by the time of the second interview showed a significant improvement in their mental health as measured by the G.H.Q. The study was important because it demonstrated deterioration in the mental health of individuals following unemployment rather than just showing differences between groups of employed and unemployed people. On the New Zealand scene, Haines and Macky's (1982) study of New Zealand school leavers found that the unemployed gained consistently higher G.H.Q. scores than an employed group matched for sex, age, years of secondary education, educational qualifications, status of father's occupation and area of residence.

\section{Moderating Factors}

Most of the work, so far, has tried to establish that unemployment is related to psychological distress and to elucidate the forms that the distress takes. Interest is now turning increasingly to factors that moderate the psychological impact of unemployment. Social support is one such factor that has received some attention. Gore (1978), as mentioned earlier in this paper, pointed to the relationship between social support and physical health. She also reported than an individual's perception of his wife, friends and relatives as being supportive would appear to moderate the severity of psychological responses to unemployment, such as depression and self-blame. A pilot study by. Figueira-McDonough (1978) of 360 family heads receiving unemployment benefits suggests that active, tangible support for an individual's everyday needs (e.g. information, referral services, baby-sitting, transportation etc.) might be more effective in moderating the negative impact of unemployment than psychological aspects of social support. She found that neighbourhood cohesion and perceived dependability of relatives, neighbours, friends and spouse contributed little to the explanation of varying levels of worry, negative moods (confusion, loneliness, unhappiness, nervousness and anger) and dissatisfaction with life among the unemployed in her study. In all probability, psychological and active tangible support are important moderating factors, although the latter may have the most beneficial effects.

"Work involvement", i.e. ". . . the degree to which a person wants to be engaged in work" (Warr et al., 1979, p.133), has been investigated as a possible moderating factor. Warr (1978) found that unemployed steel workers who stated that they were actively seeking work reported poorer psychological well-being than those who were not looking. Stafford et al. (1980) looked at work involvement among poorly qualified school leavers and found that the unemployed who were less motivated to work had lower G.H.Q. scores (i.e. better mental health) than those who were highly motivated. So a strong motivation to work is far from psychologically beneficial to the unemployed, although it may procure them a job more rapidly than otherwise and thus improve their well-being.

Other factors affecting the impact of unemployment include the following: (a) length of unemployment. Hepworth (1980) found poorer psychological well-being with a longer period spent unemployed, although this was not confirmed by other studies (Hartley, 1980; Haines and Macky, 1982). If adaptation to unemployment does occur, as one developmental model suggests, then there may not be a linear relationship between length of unemployment and deleterious effects. (b) the age of the unemployed. Several studies have pointed to differences in psychological well-being among the unemployed that are 
associated with age (c.f. Warr, 1978; Hepworth, 1980), but the results from these studies conflict, and no useful conclusions can yet be drawn. (c) the unemployed person's ability to occupy their free time meaningfully (Hepworth, 1980; Swinburne, 1981), and finally, (d) the relative amount of economic deprivation that unemployment brings about.

\section{Unemployment and Social Attitudes}

Jahoda (1979) stated that the public debate during the 1930s was between those who saw mass unemployment as leading to organized revolution and those who saw it as resulting in apathy. Eisenberg and Lazarsfeld's (1938) review concluded that the unemployed are not inclined to left-wing revolutionary activity. Unemployment did seem to engender some changed political attitudes, with more discontent about the government and the economic order being expressed. However, fascist attitudes seemed to be more common than socialist ones. In recent times Brotherton and Morley-Bunker (1980) found no significant differences in attitudes to unemployment or to social institutions or society generally between unemployed and employed residents of Nottingham. Research on the social attitudes of the unemployed is meagre at the moment but it seems likely that apathy is the common response.

\section{Unemployment and Special Groups}

Unemployment affects different individuals in different ways by virtue of their individuality, and also by virtue of their membership of various social groups. Certain social groups (e.g. racial minorities, women, school leavers) are more likely to become unemployed, but there is little information on how group membership affects the experience of unemployment. Studies to be reviewed below which look at research on women, school-leavers, middle-class men and racial minorities, do indicate some differential effects.

\section{Women}

Little research has been done on the psychological effects of unemployment among women, presumably because work is not seen as being as crucial to women's identity as it is to men's. This prejudicial attitude often leads to cries for married women to leave the workforce in times of unemployment (e.g. Thompson, 1981). Another factor which perhaps has led to this relative unconcern is that the true extent of women's unemployment is even more strongly underestimated in official figures than is men's. Since in New Zealand married women do not receive an unemployment benefit, they have little incentive to register as unemployed. Unemployed solo mothers receive Domestic Purpose Benefits and so there is no financial gain for them in registering. A striking feature of the female workforce is underemployment rather than just unemployment, as Shipley's (1982a, 1982b) current work in Palmerston North suggests. Her preliminary analysis of 70 unemployed female subjects shows that 12 were without work and seeking a full-time job 17 were without work and seeking a part-time job, 16 were underemployed, i.e. part-time workers wanting more work, 5 were school students seeking work, and 20 were discouraged job-seekers, i.e. would like a job but were not looking. But only four of these 70 women were registered unemployed with the Labour Department. Shipley concluded her preliminary report by saying: ". . . it is already apparent that some identifiable effects of unemployment are specifically female e.g. unwanted economic dependence on men." (1982a).

Hancock entitled her 1981 study of women made redundant by the closure of Mosgiel "It Just Doesn't Seem to Matter What Happens to Women". They found it harder than did the men to obtain re-employment, and as they were often ineligible for the dole, their standard of living dropped considerably causing financial hardship. Hancock documented 
the particular effect of unwanted economic dependence on their husbands, as well as the usual feelings of loneliness, anxiety and boredom.

\section{School-leavers}

Increasing concern has been expressed in the press at the plight of unemployed schoolleavers, along with fears that unemployment at that particular age might impair the development of work habits, leading to unemployability and the development of anti-social habits. Studies mentioned earlier clearly demonstrate the harmful effects of unemployment on school-leavers (e.g. Warr, 1980; and in New Zealand, Haines and Macky, 1982), but it has not been demonstrated that the experience is worse for them than for other unemployed groups. Indeed Gurney (1980) has suggested that “. . . school leavers do not have an established occupational identity, therefore their experience of being without a job cannot be primarily one of loss but must rather be one of frustrated progression" (p.205). Using an Eriksonian developmental model, Gurney did demonstrate that school-leavers who found work (particularly girls) showed significant psycho-social development, whereas those who returned to school or became unemployed did not.

\section{Middle-class men}

Most studies of the unemployed have focussed on lower socio-economic groups. However, concern has often been expressed for middle-class men who have become redundant, because they have so far to fall economically and socially, and because they are less likely to know others in the same position as themselves. Two studies of unemployed managers (Swinburne, 1981 and Hartley, 1980) showed them to be coping rather well, although, as has been mentioned, they were in re-training courses and were unrepresentative of middle-class men generally.

\section{Racial minorities}

Various racial groups have figured in existing studies of unemployed, but there is little information on whether members of different racial groups react differently to unemployment. It has been documented that attitudes to work vary across cultures, so perhaps attitudes to and responses to unemployment vary as well. In New Zealand there has been no substantial research on the psychological reactions of Maoris and Pacific Islanders to unemployment, and because rates of unemployment are very high among Polynesians, the matter urgently requires further exploration.

\section{Conclusions}

Overall, the studies do provide evidence that unemployment has serious consequences for mental and physical health, but many are characterized by methodological deficiencies. For example: (1) With the exception of the work done in the United States by Kasl and colleagues (Cobb and Kasl, 1972; Kasl, Gore and Cobb, 1975; Gore, 1978) and in Britain by Banks et al., 1980; Stafford et al., 1980 and Warr, 1980, most studies are cross-sectional rather than longitudinal. Thus they do not establish a relationship between unemployment and psychological distress as convincingly as do longitudinal studies, and they do not usually distinguish short-term from long-term effects.

(2) Some studies omit control groups and simply compare one subgroup of the unemployed with another (e.g. Singh and Kumar, 1976; Figueira-McDonough, 1978) or compare the unemployed with data from other studies of the employed (e.g. Hepworth, 1980). Without controls, such studies are often in a poor position to assert that unemployment is an important factor in the characteristics they describe.

(3) The samples are often unrepresentative of the unemployed and are usually very small. It is rare for a sample to be obtained by any random sampling methods: O'Brien and Kabanoff (1979) and Shipley (1982) are notable exceptions. The collection of subjects as 
a matter of convenience because they are available in dole queues or retraining courses leaves much to be desired.

(4) With the exception of Stafford et al.'s (1980) study, most of the research reviewed has tended to use somewhat elementary statistical analyses of the data. Much of the analysis is of necessity correlational, making causal interpretation dangerous, and ". . . little attempt has been made to go beyond simple bivariate relationships to explore systematically the way in which the variables under study act together to predict an individual's wellbeing." (Stafford et al., p.282).

(5) The unemployed are too often seen as an homogenous group, and insufficient attention is paid to the differences among them.

(6) Theoretical perspectives are not yet well developed. Obviously there is a need for more information and information of better quality about the unemployed. In particular, the role of moderator variables needs further study, as does the impact of unemployment on different social groups. Local research should be accorded high priority, since generalizations from the overseas research may be inappropriate given our unique cultural conditions. The relatively high levels of unemployment in New Zealand at present seem unlikely to decrease in the near future and may well become a permanent feature of our society. This will have a severe influence on the mental health and psychological well-being of an increasing number of people. It seems clear that from a psychological viewpoint, there is a need for either (1) a return to full employment conditions; (2) the development of more flexible arrangements to enable more of the workforce to participate in the work available, or (3) a change in the attitudes so that paid work is no longer the key to selfidentity, and lack of paid work could be a positive choice.

\section{References}

Ahr, P.R., Gorodezky, M. and Cho, D. (1981) Measuring the relationship of public psychiatric admissions to rising unemployment Hospital and community psychiatry 32(6):398-401.

Banks, M.H., Clegg, C., Jackson, P., Kemp, N., Stafford, E. and Wall, T. (1980) The use of the General Health Questionnaire as an indicator of mental health in occupational studies Journal of occupational psychology 53:187-194.

Bradburn, N.M. (1969) The structure of psychological well-being Chicago, Aldine.

Brenner, M.H. (1973) Mental illness and the economy Cambridge, Mass., Harvard University Press.

Brenner, M.H. (1976) Reply to Mr Eyer International journal of health services 6(1): 149-155.

Brenner, M.H. (1977) Personal stability and economic security Social policy June:2-4.

Brenner, M.H. (1979) Mortality and the national economy: A review, and the experience of England and Wales, 1936-76 Lancet Sept. 15: 568-573.

Brotherton, C. and Morley-Bunker, N. (1980) Unemployment and the underemployment of psychology. Paper presented to British Psychological Society, Aberdeen.

Christchurch Employment Advisory Committee (1979) Study of unemployed youth in Christchurch Christchurch.

Cobb, S., and Kasl, S.V. (1972) Some medical aspects of unemployment Industrial gerontology 12:8-15.

Daniel, W.W. (1974) A national survey of the unemployed London, Political and Economic Planning, broadsheet No. 546.

Dimsdale, J.E., Eckenrode, J., Haggerty, R.J., Kaplan, B.H., Cohen, F. and Dornbusch, S. (1979) The role of social supports in medical care Social psychiatry 14(4):175-180. 
Eisenberg, P. and Lazarsfeld, P.F. (1938) The psychological effects of unemployment Psychological bulletin 35:358-389.

Eyer, J. (1976a) Review of Mental Illness and the Economy International journal of health services 6(1):139-148.

Eyer, L. (1976b) Rejoinder to Dr Brenner International journal of health services 6(1): 157-167.

Figueira-McDonough, J. (1978) Mental health among unemployed Detroiters Social service review 52(3):383-399.

Goldberg, D.P. (1972) The detection of psychiatric illness by questionnaire London, Oxford University Press.

Goldney, R.D. and Burvell, P.W. (1980) Trends in suicidal behaviour and its management Australian and New Zealand journal of psychiatry 14:1-15.

Gore, S. (1978) The effect of social support in moderating the health consequences of unemployment Journal of health and social behaviour 19 (June): 157-165.

Gould, T. and Kenyon, J. (1972) Stories from the Dole Queue London, Temple Smith.

Gurney, R.M. (1980) The effects of unemployment on the psycho-social development of school-leavers Journal of occupational psychology 53:205-213.

Gurney, R.M. and Taylor, K. (1981) Research on unemployment: defects, neglect and prospects. Bulletin of the British Psychological Society 34: 349-352.

Haines, H. and Macky, K. (1982) Employed and unemployed school-leavers in a New Zealand community. In M. Abbott (Ed.) Mental Health Foundation of New Zealand/ New Zealand Psychological Society Symposium on Unemployment Auckland, Mental Health Foundation.

Hancock, M. (1981) It just doesn't seem to matter what happens to women Auckland, N.Z. Working Womens Council.

Hartley, J.F. (1980) The impact of unemployment upon the self-esteem of managers Journal of occupational psychology 53:147-155.

Hayes, J. and Nutman, P. (1981) Understanding the unemployed: The psychological effects of unemployment London, Tavistock.

Hepworth, S.J. (1980) Moderating factors of the psychological impact of unemployment Journal of occupational psychology 53:139-145.

Hesketh, B. (1982) Psychological aspects of unemployment. In M. Abbott (Ed.) Mental Health Foundation of New Zealand/New Zealand Psychological Society Symposium on Unemployment Auckland, Mental Health Foundation.

Hill, J. (1978) The psychological impact of unemployment New society 43(798): 118-120.

Howell, R.H., White, E.L., Monigatti, D., Pidd, A., Rawnsley, B. and Webster, G. (1980) Fatal and non-fatal deliberate self-harm in the Wellington region 1978: A social analysis New Zealand medical journal 92:468-471.

Jahoda, M. (1979) The impact of unemployment in the 1930s and the 1970s Bulletin of the British Psychological Society 32:309-314.

Jahoda, M., Lazarsfeld, P.F. and Zeisl, H. (1972) Marienthal : The sociography of an unemployed community London, Tavistock. (Originally published 1933).

Kasl, S.V., Gore, S. and Cobb, S. (1975) The experience of losing a job: Reported changes in health, symptoms and illness behaviour Psychosomatic medicine 37(2): 106-121. 
Kelvin, P. (1980) Social Psychology 2001: The social psychological bases and implications of structural unemployment. In R. Gilmour and S. Duck (Eds.) The Development of social psychology. London, Academic Press.

Lester, D. (1970) Suicide and unemployment: A re-examination Archives of environmental health 20 (Feb.):277-278.

MacDonald, M., Pearce, N., Salter,D. and Smith, A.H. (1982) Health consequences of unemployment - will effects of recent rises in New Zealand unemployment become apparent in national health statistics? In M. Abbott (Ed.) Mental Health Foundation of New Zealand/New Zealand Psychological Society Symposium on Unemployment Auckland, Mental Health Foundation.

Marsden, D. and Duff, E. (1975) Workless: Some unemployed men and their families Harmondsworth, Middlesex, Penguin.

O'Brien, G.E. and Kabanoff, B. (1979) Comparison of unemployed and employed workers on work values, locus of control and health variables Australian psychologist 14(2):143-154.

Olsen, J. and Lajer, M. (1979) Violent death and unemployment in two trade unions in Denmark Social psychiatry 14(3):139-145.

Porterfield, A.L. and Gibbs, J.P. (1960) Occupational prestige and social mobility of suicides in New Zealand. American journal of sociology 66:147-152.

Rees, W.L. (1981) Medical aspects of unemployment British medical journal 283 (Dec.): $1630-1631$.

Shipley, S. (1982a) The specific nature and effects of women's unemployment. In M. Abbott (Ed.) Mental Health Foundation of New Zealand/New Zealand Psychological Society Symposium on Unemployment Auckland, Mental Health Foundation.

Shipley, S. (1982b) Women's unemployment. In H. Haines (Ed.) Women's studies conference papers '82 Auckland, Women's Studies Assn. (N.Z.).

Singh, S.B.P. and Kumar, D. (1976) Anxiety as a function of unemployment and education Indian journal of applied psychology 13(1):38-41.

Stafford, E.M., Jackson, P.R. and Banks, M.H. (1980) Employment, work involvement and mental health in less qualified young people Journal of occupational psychology 53:291-304.

Swinburne, P. (1981) The psychological impact of unemployment on managers and professional staff Journal of occupational psychology 54:47-64.

Thompson, B. Job stealers? Listener, July 11, 1981.

Tiffany, D.W., Cowan, J.R. and Tiffany, P.M. (1970) The unemployed: A socialpsychological portrait Englewood Cliffs, NJ., Prentice-Hall.

Turtle, A., Cranfield, D., Rogers, D.H., Reuman, B. and Williams, J. (1978) Life-Not In It: A psychological comparison of employed and unemployed Sydney youth Vocational guidance research bulletin April:73-81.

Warr, P. (1978) A study of psychological well-being British journal of psychology 69: 111-121.

Warr, P. (1980) Studies of psychological well-being unpublished paper presented to the British Psychological Society Symposium on Unemployment, London, December.

Warr, P, Cook, J. and Wall, T. (1979) Scales for the measurement of some work attitudes and aspects of psychological well-being Journal of occupational psychology 52: 129-148. 